\title{
Hydatid Disease of the First Rib Causing Thoracic Outlet Syndrome
}

\author{
Suat Gezer ${ }^{\mathrm{a}}$ Tamer Altınok ${ }^{\mathrm{a}}$ Yetkin Ağaçkıran ${ }^{\mathrm{b}}$ İrfan Taştepe ${ }^{\mathrm{a}}$ \\ Departments of ${ }^{a}$ Thoracic Surgery and ${ }^{b}$ Pathology, Atatürk's Chest Diseases and Thoracic Surgery Training and \\ Research Hospital, Ankara, Turkey
}

\section{Key Words}

Hydatid disease $\cdot$ Chest wall $\cdot$ Thoracic outlet syndrome

\begin{abstract}
Objective: To present a case of hydatid disease of the first rib as a rare cause of thoracic outlet syndrome. Clinical Presentation: A 57-year-old female patient who had suffered from pain on the left shoulder radiating to the arm and numbness and weakness on the left arm for 3 months was admitted to our hospital. She had undergone an operation due to a mass lesion of the first rib compressing the thoracic outlet which was detected in the preoperative examinations. During the intraoperative examination it was decided that the lesion was a hydatid cyst and the first rib was totally resected. Conclusion: This report shows that hydatid disease should be taken into consideration amongst the tumoral diseases of the first rib as a very rare cause of thoracic outlet syndrome.

Copyright $\odot 2007$ S. Karger AG, Basel
\end{abstract}

\section{Introduction}

Hydatid disease is a parasitic disease caused by Echinococcus cestode [1]. Despite the frequency of hydatid disease of the liver and lung in endemic countries (including Turkey), hydatid disease of bone, especially of

\section{KARGER}

Fax +41613061234

E-Mail karger@karger.ch

www.karger.com
(C) 2007 S. Karger AG, Basel

1011-7571/07/0161-0068\$23.50/0

Accessible online at:

www.karger.com/mpp ribs, is very rare. In this report, we present a case of hydatid disease of the first rib causing thoracic outlet syndrome (TOS).

\section{Case Report}

A 57-year-old female patient who had complaints, including pain on the left shoulder radiating to the arm and numbness and weakness on the left arm, for 3 months was admitted to our hospital. Physical examination was normal except for positivity of Adson and Roos tests on the left arm. Laboratory examinations were unremarkable.

Chest radiography revealed a homogeneous region of increased density $5 \mathrm{~cm}$ in diameter in the left upper zone (fig. 1a). Thoracic computed tomography (CT) showed a lytic and expanding lesion on the lateral site of the left first rib with adjacent lobulated contoured soft tissue (fig. 1b). At this stage plasmocytoma, chondrosarcoma, osteochondroma and metastasis were considered in radiological differential diagnosis. Unfortunately, thoracic magnetic resonance (MR) imaging did not aid in differential diagnosis (fig. 1c-d). Furthermore, there was no involvement of the zone in bone scintigraphy. Fine needle aspiration biopsy of the mass was performed and coagulation necrosis was seen in histopathological examination of biopsy material.

Surgery was planned for diagnosis and treatment. After a high left posterolateral thoracotomy, a soft mass $(3 \times 8 \times 8 \mathrm{~cm})$ occupying the whole first rib and extending to the anterior end of

This study was presented at the 14th European Respiratory Society Annual Congress, Glasgow, UK, September 4-8, 2004. 
the second rib was observed. The posterior end of the second rib was released and divided. When the posterior end of the first rib was divided, liquefied cuticle membrane and purulent drainage was observed. Daughter cysts were aspirated from the expanded medulla of the first rib. It was decided intraoperatively that the lesion was hydatid disease and the first rib was totally resected. Because of the diagnosis of hydatid disease, the second rib was not removed and the divided posterior end was repaired with steel sutures. Compression of the subclavian vessels and brachial plexus was observed during the dissection of the lesion from the apical region. Histopathological examination of the specimen confirmed the diagnosis of hydatid disease (fig. 2).

Albendazole treatment $(15 \mathrm{mg} / \mathrm{kg})$ was begun on the first postoperative day. Radiologic investigation of the cranium and abdomen was performed postoperatively for a possible multiorgan hydatid disease but none was detected. The patient was discharged on the 7 th postoperative day without complication. No complication or recurrence was detected during the 15-month follow-up period. The complaints, that included pain on the left shoulder radiating to the left arm and numbness and weakness on the left arm, were relieved.

\section{Discussion}

Hydatid disease is a parasitic disease that is frequent in sheep and cattle raising countries that have poor sanitary conditions [1]. Liver (65\%) and lung (25\%) are the organs most frequently involved; bone involvement is very uncommon $(0.9-4 \%)$ and generally considered as a primary site [2]. Costal hydatid disease is very rare, even in the countries where the disease is endemic. Hydatid disease in the first rib causing TOS by compression of subclavian vessels and brachial plexus is an unexpected condition.

Laboratory tests and radiological examinations are frequently nondiagnostic for costal hydatid disease as in this case. The preliminary diagnosis of tumoral disease of the first rib made us consider surgery.

TOS results from the compression of the neurovascular structures at the superior thoracic aperture. The syndrome has been attributed to cervical ribs, long transverse processes, first thoracic ribs, compression by the scalene muscles, clavicle fractures and tumors at the thoracic outlet [3]. Our patient's complaint of shoulder and arm pain, intermittent paresthesia and weakness in the arm made us consider TOS, a conclusion that was supported by the positive tests of Adson and Roos during the physical examination. Intraoperatively we observed that the lesion was compressing the subclavian vessels and brachial plexus. For the investigation of TOS, visualization of the compressing lesion with radiological studies, especially with MRI, and electromyelography (EMG)
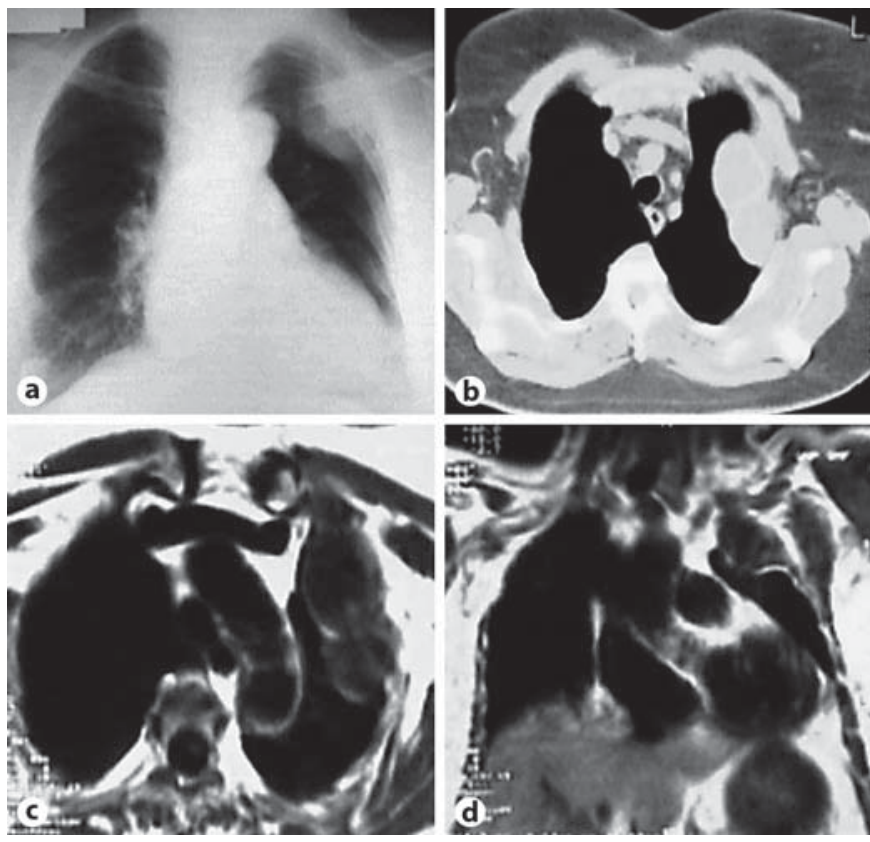

Fig. 1. a Chest X-ray showing a homogeneous region of increased density $5 \mathrm{~cm}$ in diameter in the left upper zone. b Thoracic CT revealing a lytic and expanding lesion on the lateral site of the left first rib with adjacent lobulated contoured soft tissue. c, d Thoracic MR images demonstrating a lytic, expanding lesion $(3 \times$ $8.5 \times 9 \mathrm{~cm})$ on the anterior site of the first rib left apical region.

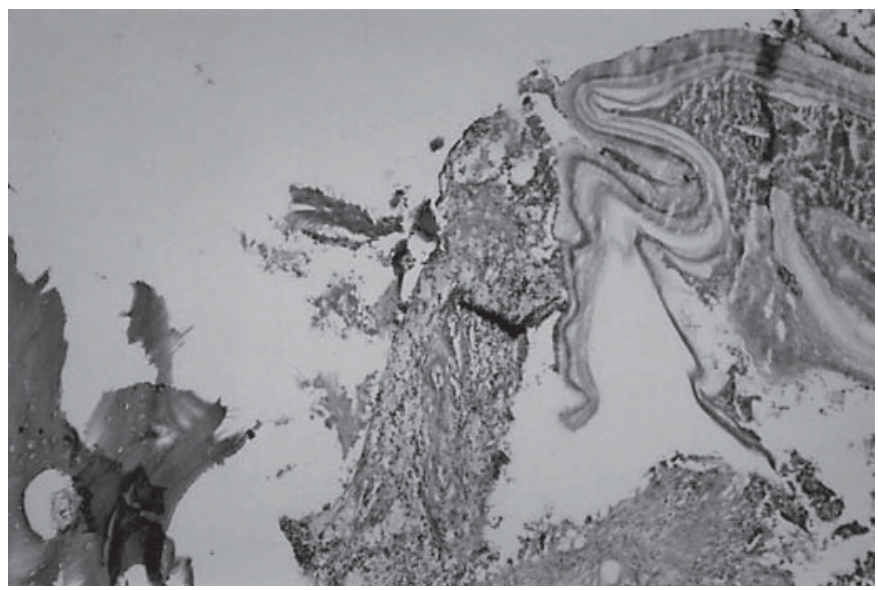

Fig. 2. Histopathology: hydatid disease. Bone spicules of the first rib on the left side and amorphous lamellar cuticle membrane inside the surrounding tissue that is infiltrated with inflammatory cells on the right side. HE. $\times 100$. 
showing possible decrease in nerve conduction velocity secondary to nerve compression are suggested. In this case we did not need to perform EMG because the lesion was absolutely visualized and the complaint of the patient was typical; an operation was inevitable. This case was highly unusual because of the etiology of TOS, which in our patient was hydatid disease of the first rib.

The gold standard for the therapy of costal hydatid disease is radical removal of the ribs or the involved chest wall [4]. We removed the diseased tissues and relieved TOS symptoms by decompression of the region through the operation.
The combination of radical surgery and medical treatment was sufficient for good clinical outcome in this patient, in agreement with Di Gesu et al. [5].

\section{Conclusion}

This report shows that hydatid disease should be taken into consideration among the tumoral diseases of the first rib as a rare cause of TOS. For the treatment of hydatid disease of the first rib, surgery is the modality of choice.

References

Karaoglanoglu N, Kurkcuoglu IC, Gorguner M, Eroglu A, Turkyilmaz A: Giant hydatid lung disease. Eur J Cardiothorac Surg 2001; 19:914-917.

2 Solli P, Carbognani P, Catellani L, Baldi P, Rusca M: Unusually located hydatid cysts miming a pulmonary tumor invaliding the spine. J Cardiovasc Surg (Torino) 2001;42: 147-149.
3 Urschel HC, Razzuk MA: Neurovascular compression of thoracic outlet: changing management over 50 years. Ann Surg 1998; 228:609-617.

-4 Stamatis G, Greschuchna D: Echinococcus cysticus costalis: report of 2 cases and review of literature. Pneumologie 1989;43:213-216.

5 Di Gesu G, Massaro M, Picone A, La Bianca A, Fiasconaro G: Bone echinococcosis. Minerva Med 1987;78:921-931. 